\title{
BMPR2 mutations in pulmonary arterial hypertension with congenital heart disease
}

\author{
K.E. Roberts*, J.J. McElroy", W.P.K. Wong*, E. Yen*, A. Widlitz , R.J. Barst ${ }^{\Uparrow}$, J.A. Knowles ${ }^{\#,+, \S, ~}$ \\ J.H. Morse*
}

BMPR2 mutations in pulmonary arterial hypertension with congenital heart disease. K.E. Roberts, J.J. McElroy, W.P.K. Wong, E. Yen, A. Widlitz, R.J. Barst, J.A. Knowles, J.H. Morse. (C) ERS Journals Ltd 2004.

ABSTRACT: The aim of the present study was to determine if patients with both pulmonary arterial hypertension (PAH), due to pulmonary vascular obstructive disease, and congenital heart defects (CHD), have mutations in the gene encoding bone morphogenetic protein receptor (BMPR)-2.

The BMPR2 gene was screened in two cohorts: 40 adults and 66 children with PAH/ CHD. CHDs were patent ductus arteriosus, atrial and ventricular septal defects, partial anomalous pulmonary venous return, transposition of the great arteries, atrioventicular canal, and rare lesions with systemic-to-pulmonary shunts.

Six novel missense BMPR2 mutations were found in three out of four adults with complete type $\mathbf{C}$ atrioventricular canals and in three children. One child had an atrial septal defect and patent ductus arteriosus; one had an atrial septal defect, patent ductus arteriosus and partial anomalous pulmonary venous return; and one had an aortopulmonary window and a ventricular septal defect.

Bone morphogenetic protein receptor 2 mutations were found in $6 \%$ of a mixed cohort of adults and children with pulmonary arterial hypertension/congenital heart defects. The current findings compliment recent reports in mouse models implicating members of the bone morphogenetic protein/transforming growth factor- $\beta$ pathway inducing cardiac anomalies analogous to human atrioventricular canals, septal defects and conotruncal congenital heart defects. The small number of patients studied and the ascertainment bias inherent in selecting for pulmonary arterial hypertension require further investigation.

Eur Respir J 2004; 24: 371-374.
Depts of *Medicine, ${ }^{*}$ Psychiatry, ${ }^{\top}$ Pediatrics, and the ${ }^{+}$Columbia Genome Center, Columbia University College of Physicians and Surgeons, and the ${ }^{8}$ New York State Psychiatric Institute, New York, NY, USA.

Correspondence: J.H. Morse, Dept of Medicine, Columbia University College of Physicians and Surgeons, New York, NY, USA. Fax: 12123054943

E-mail: jhm4@columbia.edu

Keywords: Bone morphogenetic protein receptor 2 mutations congenital heart defects eisenmenger syndrome pulmonary hypertension

Received: February 132004

Accepted after revision: May 122004

This study was supported by the Stony WoldHerbert Foundation (K.E. Roberts), the Pulmonary Hypertension Association (W.P.K. Wong) and National Institute of Health-Heart Lung 60056 (J.H. Morse).
Pulmonary arterial hypertension (PAH) consists of a group of vascular abnormalities with elevated pulmonary arterial pressure and pulmonary vascular resistance. The clinical spectrum includes familial and sporadic idiopathic PAH (IPAH) (previously referred to as primary pulmonary hypertension), as well as PAH related to congenital heart disease (CHD), portal hypertension, connective tissue diseases, HIV-infection and appetite suppressant exposure [1]. Germline mutations of bone morphogenetic protein receptor (BMPR)-2, a member of the transforming growth factor (TGF)- $\beta$ superfamily, have been found in familial and sporadic forms of IPAH [2-5], and in appetite-suppressant PAH [6], but not in PAH with HIV infection or PAH with connective tissue diseases [7, 8].

BMPR2 mutations have not been previously reported in $\mathrm{PAH}$ with CHD (PAH/CHD) in whom the PAH is due to pulmonary vascular obstructive disease. The natural history of CHD associated with large systemic-to-pulmonary shunts (e.g. atrial and ventricular septal defects, patent ductus arteriosus) results in pulmonary vascular obstructive disease, i.e. the Eisenmenger syndrome (ES) [9]. Approximately one third of all patients with CHD who do not undergo early "corrective" surgery, or who die from other causes, will die from pulmonary vascular disease [10]. Although the pathophysiological mechanisms, which lead to the histopathological changes seen in ES, are not completely understood, CHD repaired within the first 2 yrs of life is unlikely to lead to pulmonary vascular disease [10]. It is unclear in certain patients with $\mathrm{CHD}$ whether the PAH results from increased flow, a primary pulmonary vascular abnormality or both.

Members of the TGF- $\beta$ /BMP signaling pathway are particularly important in vasculogenesis and embryonic heart development [11-16]. Heterodimers of BMPR2 form a heterotetramer with type-1 receptors, BMPR1a (activin receptorlike kinase (ALK)-3) and BMPR1b (ALK6), in the presence of a BMP ligand such as BMP2 or BMP4. Mice with tissuespecific inactivation of ALK3 (BMPRla) have abnormal endocardial cushion morphogenesis [11, 13]. BMPR2 has been implicated in abnormal septation in the mouse, resulting in a conotruncal abnormality, i.e. truncus arteriosus [15]. JIAO et al. [16] has reported that cardiac muscle conditional knockout of BMP4 results in reduced atrioventricular septation.

To ascertain whether genetic mutations either predispose to PAH/CHD in general, or to a specific cardiac abnormality, the DNA sequence of the BMPR2 gene was determined in two patient cohorts; 40 adults and 66 children with PAH/CHD.

\section{Material and methods}

\section{Study subjects}

All studies and procedures were approved by the Columbia Presbyterian Medical Center Institutional Review Board (Columbia University, New York, NY, USA) and comply 
with the Declaration of Helsinki. The study group consisted of two cohorts; 66 children (aged $<18$ yrs) and 40 adults (aged $\geqslant 18$ yrs) with PAH/CHD. The diagnosis of each CHD was determined echocardiographically. The diagnosis of $\mathrm{PAH}$ due to pulmonary vascular obstructive disease was confirmed by right heart catheterisation demonstrating mean pulmonary arterial pressure $>3.3 \mathrm{kPa}(25 \mathrm{mmHg})$, mean pulmonary capillary wedge pressure $<2 \mathrm{kPa}(15 \mathrm{mmHg})$ and pulmonary vascular resistance index $>3 \mathrm{Wood}$ units $\cdot \mathrm{m}^{-2}$. All patients underwent acute vasodilator drug testing during the right heart catheterisation. Evaluation and work-up excluded other causes of PAH, such as IPAH, PAH with HIV infection, connective tissue diseases or appetite-suppressant drug exposure. None of the patients reported a family history of PAH.

\section{Mutational analysis of BMPR2}

The 13 exons and flanking intron sequences of BMPR2 were mutation screened by denaturing high-pressure liquid chromotography (dHLPC; Transgenomics, Inc., Omaha, NE, USA) as previously described [2]. All samples with inconclusive or mutation-suggestive $\mathrm{dHPLC}$ results were sequenced bidirectionally using the Big Dye $\mathbb{R}$ Terminator v1.1 Cycle Sequencing Kit (Applied Biosystems, Foster City, CA, USA), using an ABI 3100. Mutation analysis was performed blind of a patient's diagnosis with the aid of Mutation Surveyor v2.0 (SoftGenetics Inc., State College, PA, USA).

\section{Results}

Table 1 illustrates the category of CHD, the number of defects repaired, and the presence of BMPR 2 mutations in the 40 adults and 66 children with PAH/CHD. All patients were nonresponders with acute vasodilator testing [17]. The predominant CHD in both cohorts was atrial and ventricular septal defects, with the majority being unrepaired. None of the patients had primum atrial septal defects. Table 2 illustrates the clinical and haemodynamic findings, and the type of BMPR2 mutation present in the six mutation-positive patients. Strikingly, most of the BMPR2 mutations observed in the adult cohort occurred in patients with atrioventricular canals (also referred to as endocardial cushion defects), and these mutations were found in three out of four $(75 \%)$ such cases. One of these patients (number 1, table 2) also had Down syndrome. The range of defects was more variable in the children. One had an atrial septal defect and patent ductus arteriosus (who also had a ring 14 chromosome, number 4 , table 2); one had an atrial septal defect, patent ductus arteriosus and partial anomalous pulmonary venous return; and one had an aortopulmonary window and a ventricular septal defect. None of the six children with atrioventricular canal type $\mathrm{C}$ had BMPR2 mutations. Five of these six children also had Down syndrome (not illustrated).

The six novel missense BMPR2 mutations were in exons 2, 3, 5 and 11. Mutations in exons 2 and 3 are in the extracellular domains of BMPR2 (hence they might interfere with heterodimer formation or ligand binding), exon 5 is in the kinase domain (responsible for phosphorylation) and exon 11 is in the long cytoplasmic tail (unknown function). Four of the changes in predicted protein sequence caused by the mutations (adults: numbers 1 and 2; children: numbers 4 and 5) alter amino acids that are conserved in evolution across human, mouse, chicken, frog and pufferfish. In contrast, the altered amino acid is conserved only in man and mouse in patients number 3 and 6 (data not shown).

The $319 \mathrm{~T}>\mathrm{C}$ mutation in exon 3 and the $140 \mathrm{G}>\mathrm{A}$ mutation in exon 2 were spontaneous, as these two mutations were not found in either parent of the BMPR2-positive PAH adult with an atrioventricular canal (number 3 ), or the child with the rare aortopulmonary window and ventricular septal defect (number 6). DNA was not available from the parents of the other mutation-positive patients.

\section{Discussion}

This is the first report of BMPR2 mutations in adults and children with $\mathrm{PAH} / \mathrm{CHD}$ in whom the $\mathrm{PAH}$ is due to pulmonary vascular obstructive disease. The $6 \%$ frequency in a combined cohort of 40 adults and 66 children is similar to the $8 \%$ frequency of BMPR2 mutations reported for $\mathrm{PAH}$ with fenfluramine derivatives [6]. However, it is in contrast to a $26 \%$ frequency in IPAH [5] and an $~ 50 \%$ frequency in familial PAH [2, 3]. A recent National Heart Lung Blood Institute/Office of Rare Diseases workshop suggests a 5-10\% frequency for IPAH [18], as do our unpublished observations.

BMPR2 mutations were found in three adults with atrioventricular canal type $C$, and in three children with an atrial septal defect and patent ductus arteriosus, an atrial septal defect/patent ductus arteriosus and partial anomalous pulmonary venous return, and a rare conotruncal CHD. None of the atrial septal defects were primum. The present authors suspect, as larger numbers of patients with $\mathrm{PAH} / \mathrm{CHD}$ are studied, BMPR2 mutations may be found in more types of CHD. In fact, the methodology used here would miss mutations leading to large deletions and mutations affecting the promoter region of BMPR2. The failure to find BMPR2

Table 1. - Category of congenital heart disease (CHD) in 40 adults and 66 children with pulmonary arterial hypertension, number of repaired $\mathrm{CHD}$, and presence of bone morphogenetic protein receptor (BMPR)-2 mutations

\begin{tabular}{|c|c|c|c|c|c|c|}
\hline & \multicolumn{3}{|c|}{ Adults } & \multicolumn{3}{|c|}{ Children } \\
\hline & Total & Repaired & BMPR2 & Total & Repaired & BMPR2 \\
\hline Patent ductus arteriosus & 2 & 0 & 0 & 6 & 3 & 0 \\
\hline ASD & 17 & 7 & 0 & 21 & 5 & $1^{\#}$ \\
\hline ASD/PAPVR & 3 & 0 & 0 & 0 & 0 & $1^{\#}$ \\
\hline Ventricular septal defect & 8 & 1 & 0 & 15 & 8 & 0 \\
\hline PAPVR & 1 & 0 & 0 & 3 & 2 & 0 \\
\hline Transposition of the great vessels & 3 & 3 & 0 & 7 & 3 & 0 \\
\hline Atrial ventricular canal & 4 & 1 & 3 & 6 & 3 & 0 \\
\hline Rare & 2 & 0 & 0 & 8 & 5 & 1 \\
\hline Total & 40 & 12 & 3 & 66 & 29 & 3 \\
\hline
\end{tabular}

Data are presented as n. ASD: atrial septal defect; PAPVR: partial anomalous pulmonary venous return. ${ }^{*}$ : both CHDs had patent ductus arteriosus. 
Table 2.-Clinical and haemodynamic findings and bone morphogenetic protein receptor (BMPR)-2 mutations in BMPR2positive children and adults with pulmonary arterial hypertension/congenital heart disease

\begin{tabular}{|c|c|c|c|c|c|c|}
\hline & Adult 1 & Adult 2 & Adult 3 & Child 4 & Child 5 & Child 6 \\
\hline Age initial cat. yrs & 19 & 57 & 19 & 3 & 13 & 3.5 \\
\hline Age at PAH diagnosis yrs & 1 & 16 & 5 & 3 & 2 & $19^{\#}$ \\
\hline Age at repair yrs & NA & NA & 4 & NA & NA & $20^{\#}$ \\
\hline Outcome/age yrs & Lost to $\mathrm{f}-\mathrm{u}$ & Lost to $\mathrm{f}-\mathrm{u}$ & Tx, 23 & A, 16 & A, 18 & $\mathrm{D}, 5$ \\
\hline Sex M/F & $\mathrm{F}$ & $\mathrm{F}$ & M & $\mathrm{F}$ & M & M \\
\hline Ethnicity & White & White & White & White & Asian & White \\
\hline Type of CHD & AVC-C & AVC-C & AVC-C & $\mathrm{ASD} / \mathrm{PDA}$ & ASD/PDA/PAPVR & AW and VSD \\
\hline PAPm kPa (mmHg) & $9.33(70)$ & ND & $10.0(75)$ & $8.13(61)$ & $9.2(69)$ & $10.0(75)$ \\
\hline RAPm kPa (mmHg) & $0.93(7)$ & ND & $1.06(8)$ & $0.53(4)$ & $0(0)$ & $0.53(4)$ \\
\hline $\mathrm{CI} \mathrm{L} \cdot \mathrm{min}^{-1} \cdot \mathrm{m}^{-2}$ & 8.3 & ND & 4.0 & 2.3 & 3.2 & 4.0 \\
\hline PVR Wood units $\cdot \mathrm{m}^{-2}$ & 18 & ND & 23 & 19 & 10 & 22 \\
\hline SVR Wood units $\cdot \mathrm{m}^{-2}$ & 8 & ND & 13 & 25 & 21 & 13 \\
\hline $\mathrm{MVSa}, \mathrm{O}_{2} \%$ & 50 & ND & 52 & 65 & 60 & 68 \\
\hline $\mathrm{Sa}, \mathrm{O}_{2} \%$ & 64 & ND & 84 & 91 & 86 & 90 \\
\hline Genetic syndrome & Down & $\mathrm{N}$ & $\mathrm{N}$ & Ring 14 & $\mathrm{~N}$ & $\mathrm{~N}$ \\
\hline \multicolumn{7}{|l|}{ BMPR2 mutation } \\
\hline Exon & 2 & 3 & 3 & 5 & 11 & 2 \\
\hline Nucleic acid change & $125 \mathrm{~A}>\mathrm{G}$ & $304 \mathrm{~A}>\mathrm{G}$ & $319 \mathrm{~T}>\mathrm{C}$ & $556 \mathrm{~A}>\mathrm{G}$ & $1509 \mathrm{~A}>\mathrm{C}$ & $140 \mathrm{G}>\mathrm{A}$ \\
\hline Amino acid change & Q42R & T102A & S107P & M186V & E503D & G47N \\
\hline Type of mutation & Missense & Missense & Missense & Missense & Missense & Missense \\
\hline
\end{tabular}

Cat.: catheterisation; PAH: pulmonary arterial hypertension; M: male; F: female; CHD: congenital heart defects; PAPm: mean pulmonary artery pressure; RAPm: mean right atrial pressure; $\mathrm{CI}$ : cardiac index; PVR: pulmonary vascular resistance; SVR: systemic vascular resistance; MVSa, $\mathrm{O}_{2}$ : mixed venous oxygen saturation; $\mathrm{Sa}_{2} \mathrm{O}_{2}$ : systemic oxygen saturation; NA: not applicable; f-u: follow-up; Tx: heart-lung transplant; A: alive; D: dead; AVC-C: complete atrial ventricular canal defect type C; ASD: atrial septal defect; PDA: patent ductus arteriosus; PAPVR: partial anomalous pulmonary venous return; AW: aortopulmonary window; VSD: ventricular septal defect; ND: not done; Down: Down syndrome; N: normal; Ring 14: ring chromosome $14 .{ }^{*}$ : months.

mutations in the children with atrioventricular canal type $\mathrm{C}$ defects may be due to the small sample size/and or the association with Down syndrome. Five of the six mutationnegative children and one of the mutation-positive adults had Down syndrome. Atrioventricular canal defects are one of the most frequent CHDs that occur with trisomy 21. Therefore, these defects may result from a different genetic mechanism than those that occur without a recognised chromosomal genetic syndrome. The child with atrial septal defect and patent ductus arteriosus (number 4) also had a ring chromosome 14, a rare abnormality associated with CHD, mental retardation and seizures. The onset of disease in individuals with PAH is thought to require a combination of two or more genetic or environmental factors, as in cancer [19]. To speculate, the interplay between a congenital syndrome, a CHD and a BMPR2 mutation could provide the required two or more "hits".

The six novel missense BMPR2 mutations in exons 2, 3, 5 and 11 have the potential to be deleterious by changing the protein sequence at evolutionary conserved amino acids and, hence, altering BMPR2 function. It is also formally possible that these DNA sequence variations could be nonpathogenetic polymorphisms. The current authors think this is unlikely, as they have not been reported in the literature [4], nor observed in $>196$ healthy individuals and $>1,000$ other PAH chromosomes that have been previously screened by the authors. Four of the six missense mutations were at sites conserved in evolution from man to the pufferfish, whereas the other two sites were conserved only in man and the mouse. Spontaneous BMPR2 mutations have also been reported previously in familial PAH [2] and in sporadic IPAH [5]. Unfortunately, parental DNA was not available for all patients to determine if spontaneous mutations are a universal finding in this category of PAH/CHD.

The types of CHD found in the BMPR2-positive patients are in accordance with reports regarding the role of the BMP pathway in embryonic cardiac development. Homozygous BMPR2 knockout mice die at gastrulation, whereas no abnormalities have been reported for the heterozygous mouse [20]. Recently, JiAO et al. [16], using a Cre/loxp recombination conditional knockout, demonstrated that BMP-4 contributes in a dose-related fashion to normal atrioventricular septation and endocardial cushion formation. In the presence of low or no BMP-4, mice had atrioventricular canals and outflow tract abnormalities. DELOT et al. [15] have created a mouse with a truncated extracellular domain of BMPR2, documenting embryonic lethality at E12, and absence of the septation of the outflow tract and aortic arch interruption, the anatomical correlate of persistant truncus arteriosus type 4A in humans [15]. BMP ligands bind to a heterodimer comprised of BMPR2, with BMPR 1a and/or BMPR $1 b$ to initiate signaling, therefore, mutations of either a ligand or of BMPR2 could be predicted to interfere with signalling.

The present study was initiated to provide a preliminary catalogue of BMPR2 mutations in patients with PAH/CHD in whom the PAH was due to pulmonary vascular obstructive disease. As BMPR2 mutations have not been previously investigated in either children or adults with CHD without $\mathrm{PAH}$, it is presently impossible to differentiate the role of increased flow versus genetic mutations in predisposing to pulmonary vascular disease. Although the definition of IPAH requires the exclusion of other causes, small anatomical congenital systemic-to-pulmonary shunts may be found. Whether these represent unrelated phenomena or genetic predisposition for IPAH with a haemodynamically insignificant congenital systemic-to-pulmonary shunt triggering the onset of the pulmonary vascular disease remains uncertain [21-23]. Although pulmonary vascular disease associated with congenital systemic-to-pulmonary shunts usually follows a period of increased pulmonary blood flow, it may occur in patients who never manifested a large left-to-right shunt. Support for this comes from the observation of severe progressive PAH following repair of atrial septal defects in two children whose mothers died from IPAH, but by definition classifiable as familial PAH [24]. Extrapolation 
from the presence of BMPR2 mutations in familial PAH and sporadic IPAH suggests BMPR2 mutations may be a risk factor for PAH/CHD.

It is anticipated that further functional investigations of specific members of the human bone morphogenetic protein/ transforming growth factor- $\beta$ pathway, aided by conditional murine knockouts, will increase knowledge of the cause(s) and interrelationship(s) between various congenital heart defects, pulmonary arterial hypertension, and the development of pulmonary vascular obstructive disease.

Acknowledgements. The authors would like to thank the patients and their physicians for their participation in these studies. They also acknowledge the generosity of the Linnen family for the gift of an HPLC apparatus.

\section{References}

1. Rich S. ed. Primary pulmonary hypertension: executive summary from the World Symposium-Primary Pulmonary Hypertension. Available at www.who.int/ncd/cvd/.pph.html; last accessed: 11 July 2001.

2. Deng Z, Morse JH, Slager SL, et al. Familial primary pulmonary hypertension (gene PPH1) is caused by mutations in the bone morphogenetic protein receptor-II gene. $\mathrm{Am}$ J Hum Genet 2000; 67: 737-744.

3. Lane KB, Machado RD, Pauciulo MW, et al. Heterozygous germline mutations in BMPR2, encoding a TGF-beta receptor, cause familial primary pulmonary hypertension. The International PPH Consortium. Nat Genet 2000; 26: 8184.

4. Machado RD, Pauciulo MW, Thomson JR, et al. BMPR2 haploinsufficiency as the inherited molecular mechanism for primary pulmonary hypertension. Am J Hum Genet 2001; 68: 92-102.

5. Thomson JR, Machado RD, Pauciulo MW, et al. Sporadic primary pulmonary hypertension is associated with germline mutations of the gene encoding BMPR-II, a receptor member of the TGF-B family. $J$ Med Genet 2000; 37: 741745 .

6. Humbert M, Deng Z, Simonneau G, et al. BMPR2 germline mutations in pulmonary hypertension associated with fenfluramine derivatives. Eur Resp $J$ 2002; 20: 518-523.

7. Nunes H, Humbert M, Sitbon $\mathrm{O}$, et al. Declining mortality from HIV-associated pulmonary arterial hypertension with combined use of highly active anti-retroviral therapy and long-term epoprostenol infusion. Am J Resp Crit Care Med 2002; 20: 518-523.

8. Morse J, Barst R, Horn E, et al. Pulmonary hypertension in scleroderma spectrum of disease: Lack of bone morphogenetic protein receptor 2 mutations. $J$ Rheumatol 2002; 11: 2379-2381.

9. $\quad$ Eisenmenger V. Z Klin Med 1897; 32, Suppl., 1.

10. Barst RJ. Primary pulmonary hypertension. In: Friedman WF, ed. Proceedings of the National Heart, Lung, and Blood Institute pediatric cardiology workshop: pulmonary hypertension. Pediatric Res 1986; 20: 816-817.

11. Schneider MD, Gaussin V, Lyons KM. Tempting fate: BMP signals for cardiac morphogenesis. Cytokine Growth Factor Rev 2003; 14: 1-4.

12. Hogan BL. Bone morphogenetic proteins: multifunctional regulators of vertebrate development. Genes Dev 1996; 10: $1580-1594$.

13. Gaussin V, Van de PT, Mishina Y, et al. Endocardial cushion and myocardial defects after cardiac myocytespecific conditional deletion of the bone morphogenetic protein receptor ALK3. Proc Natl Acad Sci USA 2002; 99: 2878-2883.

14. Pierpont ME, Markwald RR, Lin AE. Genetic aspects of atrioventricular septal defects. Am J Med Genet 2000; 97: 289-296.

15. Delot EC, Bahamonde ME, Zhao M, Lyons KM. Development and Disease. BMP signaling is required for septation of the outflow tract of the mammalian heart. Development 2003; 130: 209-220.

16. Jiao K, Kulessa H, Tompkins K, et al. An essential role of Bmp4 in the atrioventricular septation of the mouse heart. Genes Dev 2003; 17: 2362-2367.

17. Barst RJ, Maislin G, Fishman AP. Vasodilator therapy for primary pulmonary hypertension in children. Circulation 1999; 99: 1197-1208.

18. Newman JH, Fanburg BL, Archer SL, et al. Pulmonary arterial hypertension: future directions report of an NHLBI/ ORD workshop. Circulation 2004 (in press).

19. Voelkel NF, Cool C, Lee SD, et al. Primary pulmonary hypertension between inflammation and cancer. Chest 1998; 114: 225S-230S

20. Beppu H, Kawabata M, Hamamoto T, et al. BMP type II receptor is required for gastrulation and early development of mouse embryos. Dev Biol 2000; 221: 249-258.

21. Bleiden LC, Moller JH. Small ventricular septal defect associated with severe pulmonary hypertension. Br Heart $J$ 1984; 52: 117-118.

22. Bisset GS, III, Hirschfeld SS. Severe pulmonary hypertension associated with a small ventricular septal defect. Circulation 1983; 67: 470-473.

23. Haworth SG. Pulmonary vascular disease in secundum atrial septal defect in childhood. Am J Cardiol 1983; 51: 265-272.

24. Morse JH, Barst RJ, Fotino M. Familial pulmonary hypertension: immunogetic findings in four Caucasian kindreds. Am Rev Respir Dis 1992; 145: 787-792. 